$\Delta \Omega(1 \rightarrow 2)$ is very simple and is given by

$$
\Delta \Omega(1 \rightarrow 2)=\frac{\Omega(1-3) \cdot \Omega(3 \rightarrow 2)}{\Omega(1-3)+\Omega(3-2)} .
$$

This expression is valid for each total angular momentum $L^{\mathrm{t}}$ of the system (ion $+\mathrm{e}^{-}$). The expres sion (3) has been pointed out rigorously by Gailitis, but it is possible to obtain (3) through the same physical arguments that A. Burgess used in his paper on recombination [5].

Let us look at the specific problem of the Ca II excitation by electron impact. This problem is a six-channel problem if one reduces $\mathrm{Ca}$ II to its first three levels: $4 \mathrm{~s}, 3 \mathrm{~d}$ and $4 \mathrm{p}$. For a given total angular momentum $L^{\mathrm{t}}$, the six associated channels are:

$$
\begin{aligned}
& 1 \equiv k_{1}^{2} ; 4 \mathrm{~s} ; l_{1}=L^{\mathrm{t}} \quad 4 \equiv k_{2}^{2} ; 3 \mathrm{~d} ; l_{4}=L^{\mathrm{t}}+2 \\
& 2 \equiv k_{2}^{2} ; 3 \mathrm{~d} ; l_{2}=L^{\mathrm{t}}-2 \quad 5 \equiv k_{5}^{2} ; 4 \mathrm{p} ; l_{5}=L^{\mathrm{t}}-1 \\
& 3 \equiv k_{2}^{2} ; 3 \mathrm{~d} ; l_{3}=L^{\mathrm{t}} \quad 6 \equiv k_{5}^{2} ; 4 \mathrm{p} ; l_{6}=L^{\mathrm{t}}+1,
\end{aligned}
$$

$k_{i}^{2}$ and $l_{i}$ being the energy and the angular momentum of the additional electron associated with the channel $i$. One sees that introduction of the level $4 \mathrm{p}$ corresponds to two new channels in the scattering problem. It follows that (3) is no longer valid. Since the interaction potential between the channels 5 and 6 is quadrupolar, and by no means weak, it is possible to show that the following is a good approximation $(i=2,3,4)$ :

$$
\Delta \Omega(1 \rightarrow i)=\frac{\Omega(1 \rightarrow 5) \cdot \Omega(5 \rightarrow i)}{\sum_{j<5} \Omega(5 \rightarrow j)}+\frac{\Omega(1 \rightarrow 6) \cdot \Omega(6 \rightarrow i)}{\sum_{j<5} \Omega(6 \rightarrow j)}
$$

Taking the $R$ matrixes computed by D. Petrini, who used the Coulomb-Born approximation [6], we have computed $\Delta \Omega(4 \mathrm{~s} \rightarrow 3 \mathrm{~d})$.

Table 1 shows the results for each total angular momentum $L^{t}$. These results show that the effects of the non-direct excitation are not negligible at all. Roughly speaking, one can assure that $Q(4 \mathrm{~s} \rightarrow 3 \mathrm{~d})$ is multiplied by 2 between the levels $3 d$ and $4 p$.

In conclusion we can say that each time one has to deal with a weak transition cross section one has to worry about the effects that the strong coupled transitions could introduce to the weak transition cross section through the process mentioned above. The particularly interesting case of $\mathrm{Fe} \mathrm{XIV}$ is under investigation now.

\title{
NOTES ON THE SUBMILLIMETER LASER EMISSION FROM CYANIC COMPOUNDS
}

\author{
W. PRETTL and L.GENZEL \\ Physikalisches Institut der Universität Freiburg i.Br., Germany
}

Received 13 October 1966

\begin{abstract}
From $\mathrm{CH}_{3} \mathrm{CN}$ and from a mixture of $\mathrm{CH}_{3} \mathrm{CN}$ and $\left(\mathrm{CH}_{3}\right)_{2} \mathrm{SO}_{4}$ laser emission additional to that already reported in the literature has been found at $119 \mu, 310.4 \mu, 310.5 \mu, 311.5 \mu, 334.4 \mu$ and $334.8 \mu$.
\end{abstract}

Several authors have reported far-infrared laser emission from cyanic compounds [1-6]. We observed with a pulsed electric discharge through $\mathrm{CH}_{3} \mathrm{CN}$ the well-known strong lines at $337 \mu$ and $310 \mu$. Furthermore we found under appropriate conditions, strongly dependent on vapor pressure, a splitting of the $310 \mu$ line into three lines at $310.4 \mu, 310.5 \mu, 311.5 \mu$ and a new line group at $334.4 \mu$ and $334.8 \mu$. The splitting of $337 \mu$ emission first reported by Kneubühl et al. [4] could be proved. 
Table 1

\begin{tabular}{|c|c|c|c|}
\hline Vapour & $\begin{array}{l}\text { Wavelength } \\
(\mu)\end{array}$ & $\begin{array}{l}\text { Optimum pres- } \\
\text { sure (Torr) }\end{array}$ & $\begin{array}{l}\text { Output peak } \\
\text { energy per } \\
\text { pulse (J) }\end{array}$ \\
\hline \multirow[t]{2}{*}{$\mathrm{CH}_{3} \mathrm{CN}$} & $\begin{array}{l}310.4 \\
310.5 \\
311.5\end{array}$ & \} & $\begin{array}{l}10^{-6} \\
10^{-6} \\
10^{-7}\end{array}$ \\
\hline & $\begin{array}{l}334.4 \\
334.8\end{array}$ & 0.5 & $\begin{array}{l}10^{-6} \\
10^{-6}\end{array}$ \\
\hline \multirow[t]{2}{*}{$\begin{array}{c}\mathrm{CH}_{3} \mathrm{CN} \\
+\left(\mathrm{CH}_{3}\right)_{2} \mathrm{SO}_{4}\end{array}$} & 119.0 & $\begin{array}{c}\mathrm{CH}_{3} \mathrm{CN}: 0.01 \\
\left(\mathrm{CH}_{3}\right)_{2} \mathrm{SO}_{4}: 0.8\end{array}$ & $10^{-5}$ \\
\hline & $\pm 0.1 \%$ & & \\
\hline
\end{tabular}

In a mixture of $\mathrm{CH}_{3} \mathrm{CN}$ and $\left(\mathrm{CH}_{3}\right)_{2} \mathrm{SO}_{4}$ with partial pressures of $10^{-2}$ Torr and 0.8 Torr resp., a strong line at $119 \mu$ was obtained. This oscillation occurred only if the electric discharge was first applied for a few minutes to $\mathrm{CH}_{3} \mathrm{CN}$ only and then $\left(\mathrm{CH}_{3}\right)_{2} \mathrm{SO}_{4}$ was added. With pure $\mathrm{CH}_{3} \mathrm{CN}$ or pure $\left(\mathrm{CH}_{3}\right)_{2} \mathrm{SO}_{4}$ an emission of this wavelength could not be observed. All lines are listed in table 1 .

The laser cavity was a glass tube $5.85 \mathrm{~m}$ long having an internal diameter of $7.2 \mathrm{~cm}$ closed at one end by a plane aluminized mirror and at the other end by a plane copper mesh. The properties of this mesh were $[7,8]$ : grating constant $=35 \mu$, grating constant to strip half breadth ratio $=8$ and reflection $=0.97$, transmission $=0.02$ all at $330 \mu$ wavelength. The radiation was coupled through the mesh to the outer detector system consisting of a Fabry-Perot-interferometer [9] to separate the

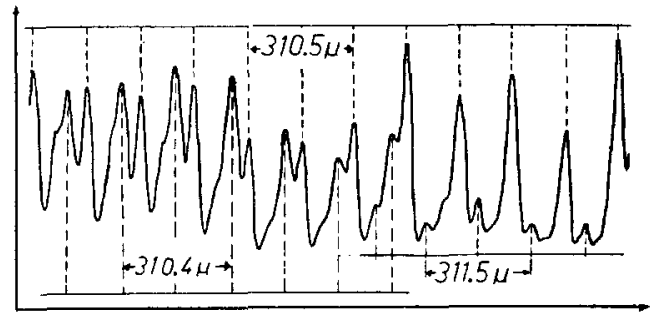

Fig. 1. Interferogram of $\mathrm{CH}_{3} \mathrm{CN}$. Three lines at $310.4 \mu$, $310.5 \mu, 311.5 \mu$. The dashed lines mark the $\frac{1}{2} \lambda$-resonances.

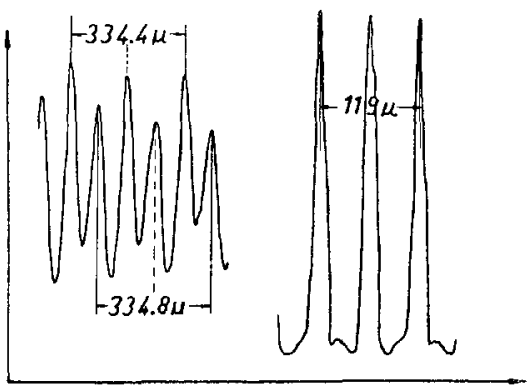

Fig. 2. Left: Interferogram of $\mathrm{CH}_{3} \mathrm{CN}$. Two lines at $334.4 \mu$ and $334.8 \mu$. With an external FPI these resonances were proved to be produced by two lines and not by one line at $167 \mu$. Right: Interferogram of $\mathrm{CH}_{3} \mathrm{CN}$ and $\left(\mathrm{CH}_{3}\right)_{2} \mathrm{SO}_{4}$. One line at $119 \mu$.

different line groups and a bolometer. The bolometer was calibrated to measure the energy per radiation pulse. The wavelength of the lines were determined by the interferometric properties of the laser cavity. The interferograms are shown in figs. 1 and 2 .

The electric pulses were produced by a $17 \mathrm{kV}$ d.c.-source and a $0.1 \mu \mathrm{F}$ condenser periodically discharged through the vapour in the cavity. The repetition frequency was $1 \mathrm{cps}$.

\section{References}

1. H. A. Gebbie, N. W. B. Stone and F. B. Findlay, Nature 202 (1964) 685 .

2. L. E.S. Mathias, A. Crocker and M. S. Wills, Electr. Letters 1 (1965) 45.

3. F. K. Kneubiih1, J.-F. Moser, H. Steffen and W. Tandler, Z. Angew. Math. Phys. 16 (1965) 560.

4. M. Camani, F.K. Kneubüh1, J.-F. Moser and H. Stef-fen, Z. Angew. Math. Phys, 16 (1965) 562.

5. H. Steffen, J.Steffen, J. -F. Moser and F. K. Kneubtihl, Phys. Letters 20 (1966) 20.

6. H. Steffen, J.Steffen, J. - F. Moser and F. K. Kneubüh1, Phys. Letters 21 (1966) 425.

7. K. F. Renk and L. Genzel, Appl. Optics 1 (1962) 643.

8. P. Vogel and L. Genzel. Infrared Phys. 4 (1964) 257.

9. R. Ulrich, K. F. Renk and L. Genzel, IEEE Transactions MTT 11 (1963) 363. 